\title{
MAGALHÃES, I. \& LEAL, M. C. D. (ORGS.) DISCURSO, GÊNERO E EDUCAÇÃO. BRASÍLIA: PLANO EDITORA: OFICINA EDITORIAL DO INSTITUTO DE LETRAS DA UNB, 2003, 186 PÁGS.
}

\author{
Resenhado por: Maria Aparecida R. Ottoni
}

Esta obra reúne trabalhos de lingüistas da Universidade de Brasília, tanto do Departamento de Lingüística, Línguas Clássicas e Vernácula quanto da Faculdade de Educação; da Universidade Federal de Goiás e da PUC/ Campinas, que buscam dar uma contribuição para o debate de um tema fundamental nos dias de hoje: a relação entre linguagem (discurso), gênero social ${ }^{1}$ e educação.

$\mathrm{Na}$ Introdução da obra, suas organizadoras apresentam uma visão geral de conceitos importantes, tais como: o de discurso e de ideologia, comparando as abordagens de diferentes autores e apontando as suas limitações e contribuições. As autoras defendem uma concepção dialética de discurso e ideologia, que abarca tanto a reprodução quanto a transformação das práticas. Elas também enfocam a Teoria Social Crítica, destacando o discurso como um momento das práticas sociais que não pode ser descartado. Essa perspectiva teórica, conforme salientam as pesquisadoras, indubitavelmente contribui para descrever, interpretar e explicar a linguagem como prática social e seu papel nas transformações da modernidade tardia, que afetam profundamente a formação dos sujeitos e sua relação com os outros. Desse modo, o discurso constitui as identidades por meio da diferença (Silva, 2000) e, nesse ponto, Magalhães e Leal lançam dois questionamentos: "Não terá chegado a hora de refletir sobre a heterogeneidade nos discursos? Não terá chegado a hora de romper com as estruturas que classificam para oprimir?"

1 Magalhães e Leal usam a expressão 'gênero social' para evitar confusão com o gênero gramatical (masculino/feminino) ou com o gênero de discurso, que definem como uma determinada seqüência lingüística associada a uma ocasião social, como a consulta médica, a aula, a entrevista televisiva. 
Tudo nos leva a crer que as autoras entendem que essa hora chegou. E, como lacuna e "lugar" de investigação, nesse amplo debate, elas apontam uma questão que não tem sido comentada por teóricos da identidade: a política da diferença só inclui os grupos sociais organizados, deixando à mercê de sua própria marginalização os segmentos sociais totalmente enfraquecidos. Como se pode ver, toda essa abordagem feita na Introdução da obra é fundamental para que os(as) leitores(as) possam melhor se situar e compreender os trabalhos desta coletânea, que se propõem a discutir, basicamente, a noção de gênero e o ensino, e são organizados em três partes, de acordo com os campos específicos de investigação.

A primeira parte, Discurso e gênero, é composta por dois capítulos: um de Astrid Sgarbieri, "Mídia, gênero e poder"; e o outro de Izabel Magalhães, "Interdiscursividade e identidade de gênero". No Capítulo 1, Sgarbieri analisa alguns aspectos lingüísticos de dois artigos publicados pela Folha de S. Paulo - "Mulheres, mulheres" e "Mulher e emprego" -, que discutem o problema do desemprego e a incorporação maciça da mulher no mercado de trabalho, apontando a relação entre o discurso e a sociedade, mediada pela cognição social, que é o foco deste capitulo. Ela parte da premissa de que a notícia na mídia é social e culturalmente determinada e, portanto, ideologicamente marcada por relações de poder. Como arcabouço teórico, baseia-se na proposta da Análise de Discurso Crítica e na noção de gênero. Sua análise, embora superficial, mostra o preconceito e a discriminação em relação à mulher no mercado de trabalho e demonstra a dificuldade que se observa na sociedade brasileira de a mulher ser aceita como força de trabalho. No Capítulo 2, Magalhães, por sua vez, focaliza a identidade de gênero em cinco números do jornal Resgatando, produzido pela equipe de pesquisa do projeto "Intertextualidade, Letramento, Identidade" com um grupo comunitário de alfabetização de jovens e adultos, no Paranoá, cidade satélite de Brasília/DF. No início de seu texto, a autora destaca que o gênero social é um dos grandes temas debatidos no cenário nacional e internacional contemporâneo e, com muita propriedade, salienta que é preciso, portanto, realizar um debate sobre ele na Lingüística, já que as relações de gênero são construídas em grande parte pela linguagem. 
Baseando-se na perspectiva da Teoria Social do Discurso e no conceito de gênero, a pesquisadora investiga também a identidade de gênero em textos publicitários, cuja discussão em sala de aula representa uma oportunidade de desenvolvimento de uma consciência crítica sobre as relações assimétricas entre os gêneros e o papel da linguagem na construção dessas relações, tanto em termos de sua reprodução como de sua transformação. Como Magalhães salienta, as ambigüidades com relação às relações de gênero social estão presentes na língua, pois decorrem da estreita ligação entre os processos sociais e lingüísticos. Assim, neste capítulo, ela examina essas ambigüidades na língua, mediante a investigação de textos e interações no contexto da produção de um jornal por alunos(as) e alfabetizadores(as) de jovens e adultos, no contexto da sala de aula e em dados de entrevistas com mulheres e homens, alfabetizandos adultos, com o intuito de responder a uma questão principal: Qual é o discurso predominante nos jornais, na sala de aula e nas entrevistas - o discurso tradicional, de controle da mulher, ou o de emancipação? Ela parte da hipótese de que o discurso tradicional coexiste atualmente com o de emancipação numa relação dialética, marcada por tensões, avanços e recuos, que podem ser detectados nos textos falados e escritos.

A autora amplia a discussão sobre a identidade, mostrando sua ligação com a Modernidade Tardia que tem afetado profundamente a identidade das pessoas, não mais vista como fixa, e seus sentimentos pessoais. Sobre esse tema, de grande relevância, Magalhães traz para o debate autores como Chouliaraki e Fairclough (1999), Giddens (1991), Hall (1997) e Bhabha (1994). Para conceituar a identidade, ela propõe discutir sua relação com a linguagem, a ideologia e o gênero social (Cameron, 1995). No final do trabalho, a discussão da identidade de gênero é ampliada e é examinada nas articulações e rearticulações entre o discurso de controle e o discurso de emancipação. A pesquisadora destaca que para a mulher constituir-se com um lugar social próprio nos domínios públicos, que são os que detêm prestígio social e poder, há que se investir em sua educação. Enfim, a conclusão propõe a emancipação da mulher mediante um letramento crítico.

Também a segunda parte, Discurso e alfabetização de adultos, constituise de dois capítulos: um de Elenita Rodrigues, intitulado "A alfabetização 
de adultos na perspectiva da consciência lingüística crítica", e um de Alexandre Ferreira da Costa, "Alfabetização de jovens e adultos e mudança social: uma abordagem discursiva para o fenômeno do analfabetismo". No Capítulo 3, o estudo de Rodrigues é dedicado a desenvolver uma pesquisa colaborativa, investigando e implementando, juntamente com algumas alfabetizadoras do programa de alfabetização de jovens e adultos da cidade do Paranoá/DF, princípios da Consciência Lingüística Crítica em sala de aula. O estudo interessa-se pelos modos como as práticas, em especial as lingüísticas, que mantêm e reproduzem modelos de dominação e sujeição na sociedade, podem ser contestadas. Como esta pesquisa também é parte do projeto "Intertextualidade, Letramento, Identidade", coordenado por Izabel Magalhães, há um diálogo entre os textos das duas autoras.

No trabalho de Rodrigues, são analisados eventos de letramento realizados em sala de aula: atividades de letramento visual crítico-funcional, de produção textual, de leitura opositiva e atividade sobre as relações de poder na sala de aula. Quanto aos realizados fora da sala de aula, destacam-se: discussão de textos teóricos com a monitora e o auxiliar e a investigação das ordens discursivas locais. A análise da autora tem como objetivo propiciar reflexões que contribuam para formulação de estratégias de fortalecimento das identidades sociais, e a análise discursiva dessas atividades demonstra que elas têm contribuído para o início da construção de uma consciência de língua, fundamental na transformação das relações de dominação. Contudo, a autora conclui que o processo de construção de uma CLC é mais lento e complexo do que imaginava. Por isso, trabalhos dessa natureza não podem nem devem ser abandonados drasticamente; pois, se o forem, a longo prazo de nada servirão.

Com relação ao Capítulo 4, nele Costa apresenta uma redefinição dos conceitos de analfabetismo e de alfabetização de jovens e adultos e também uma revisão de referenciais teóricos que tornem possível tratar dessas questões. A partir da consideração da formação do movimento de alfabetização de jovens e adultos no Distrito Federal, discute as condições de possibilidade do estudo dos problemas e das práticas relacionados à desigualdade social relativa ao letramento. Baseando-se na Teoria Social do Discurso e em estudos sobre o letramento, ele propõe uma concepção discursiva do letramento e focaliza os processos de disciplinamento e de conscientização 
realizados na e pela linguagem. Em sua conclusão, o autor mostra que nas sociedades modernas (incluindo o contexto brasileiro), a alfabetização de jovens e adultos tem sido usada como um tipo de tecnologia discursiva; isto é, como uma forma de orientar ou produzir mudança social. Ele considera que uma concepção discursiva do processo de alfabetização pode oferecer um maior equilíbrio entre o caráter 'positivo' e o 'negativo' do processo, mas que, de um modo geral, a avaliação das práticas alfabetizadoras tem sido feita somente em relação ao primeiro caráter. No final, ele relembra e esclarece que o objetivo da discussão é contribuir para a compreensão das dimensões 'geométricas' da desigualdade social, nos aspectos relativos ao discurso e ao letramento. E, em última análise, o tratamento 'aritmético' da diminuição da pobreza, segundo o autor, é um redimensionamento 'funcional' que atende muito mais às necessidades das camadas sociais já favorecidas.

Quanto à terceira parte, Discurso: escola, família e comunidade, ela é composta de 3 capítulos: um de Maria Christina D. Leal, intitulado "Consciência lingüística crítica e mudança nas características da identidade docente"; um de Josênia Antunes Vieira, "Práticas discursivas no letramento escolar e familiar"; e o último da coletânea "O papel do(a) interlocutor(a) no discurso: paradigmas sociolingüísticos”, de Stella Maris Bortoni-Ricardo. No Capítulo 5, Leal focaliza, por um lado, algumas das razões do baixo desempenho dos estudantes brasileiros na leitura e compreensão de textos, com ênfase ao papel do(a) professor(a), e, por outro, apresenta os resultados de uma pesquisa, intitulada "Língua Materna e Cidadania Fase 2", desenvolvida de 1995 a 1997, na Escola Normal de Taguatinga, DF, juntamente com uma professora de Língua Portuguesa, em que investiga como uma professora de português pode desenvolver uma conscientização crítica da linguagem e quais as mudanças nas características de sua identidade durante o processo.

Ela desenvolve uma análise de discurso crítica de textos dos relatórios escritos bimestrais da professora e de textos de transcrição de fitas gravadas em áudio e destaca a relação entre as posições de sujeito ocupadas pela professora e as características de sua identidade, no início da pesquisa, durante o seu desenvolvimento e ao término. São focalizados aspectos ideológicos e questões de poder. Na conclusão, são apresentados 
indícios de fortalecimento tanto da professora quanto dos(das) alunos(as), bem como de um discurso emancipatório da professora. Todas as mudanças desenvolvidas durante a pesquisa representam práticas que se opõem às tradicionalmente sustentadas pela ideologia e constroem o fortalecimento dos sujeitos. Nessa trajetória, Leal observa que novos traços na caracterização da identidade da professora vão-se delineando. Esta passa a ser alguém que planeja, cria, critica, decide, investiga, administra, dialoga; portanto, alguém com a identidade bem diferente da de "repassadora de informações", papel delimitado pela ideologia e amplamente aceito pela sociedade. Enfim, com essas mudanças na identidade, a pesquisadora mostra que a professora apresenta o perfil de alguém capaz de desenvolver um ensino de língua portuguesa que possa contribuir para a construção dos alunos como sujeitos críticos, participantes; como o que se deseja para um cidadão ou cidadã.

Já no Capítulo 6, Vieira, por sua vez, discute as práticas comunicativas construídas nas relações discursivas entre a família e a escola, no Paranoá. Baseando-se na proposta da consciência lingüística crítica, nos estudos sobre letramento como prática social e na metodologia etnográfica, a pesquisa investiga os eventos e as práticas de letramento na vida diária da criança em fase de aquisição de leitura e de escrita. Os dados foram coletados por meio da observação direta e o corpus de sua pesquisa é composto por: informações e depoimentos colhidos junto a seis famílias a respeito da comunicação com a escola; entrevistas não-estruturadas com dirigentes da escola e com as famílias; fotografias e correspondências escritas. A autora acredita que, como a escola é um domínio com práticas de letramento específicas, com pessoas especiais, com modos e com atitudes definidas e sobretudo com um discurso pedagógico próprio, ela deve ser estudada; porém, salienta que os estudos sobre letramento não devem se restringir ao âmbito escolar. Assim, por entender o letramento como prática social construída, como produto prioritariamente social, investiga como acontecem essas práticas no dia a dia das famílias e nas atividades cotidianas da escola. Contudo, podemos perceber que Vieira, ao tratar das Práticas discursivas construídas entre família e escola, deixa uma grande lacuna por não estabelecer uma relação dialógica com obras, como: Local Literacies, de Barton e Hamilton (1998) e Situated Literacies, também desses dois autores em 
parceria com Ivanic (2000), as quais apresentam uma contribuição valiosa para análise desse tipo de prática de letramento. É importante observarmos, também, que a autora, ao analisar um bilhete-aviso, copiado do quadro-negro por um(a) aluno(a), afirma que ele foi escrito sem monitoramento em português-padrão. Todavia, o que ela apresenta como comprovação de sua afirmativa pode ser interpretado como uma "falha" no ato de copiar e, não, propriamente, uma questão de "problema de redação" por parte do professor.

Por outro lado, Vieira faz uma interessante abordagem da influência da "bolsa-escola" na mudança das práticas discursivas escolares, na redução da evasão escolar e do nível de faltas dos(as) alunos(as) às aulas, e no aumento do interesse das famílias pelas atividades escolares, mostrando que está em curso uma mudança significativa no discurso familiar e escolar. Entretanto, apesar de tudo isso, a autora conclui que as práticas discursivas entre a escola e a família são assimétricas e que não há diálogo. Portanto, essas duas instituições devem procurar romper os padrões de reprodução da não-interação e devem descobrir novas formas de interação.

Com relação ao Capítulo 7, o último da obra, nele, Bortoni-Ricardo investiga uma resposta, na dinâmica dos fenômenos psicossociais de atitudes, de motivações e, principalmente, da afirmação da identidade, para a questão "Por que as pessoas mudam sua forma de falar nas diversas situações?”. A autora focaliza aspectos da variação lingüística: a finalidade de marcar a identidade social, a influência do 'outro' na produção da fala, e destaca o papel do(a) interlocutor(a). Ela apresenta três paradigmas que podem ser visualizados na evolução da sociolingüística a partir da década de sessenta e, para ilustrar o processo de identificação com o outro, com o grupo de referência, de que trata Le Page (1975/1980), são apresentados e analisados dois episódios de usos cotidianos da escrita. A análise da autora é bem interessante, uma vez que focaliza diversos aspectos, como: a preocupação de alguns falantes em se legitimarem como líderes comunitários; a dimensão da identidade social dos falantes que se sobressai e o papel social dos mesmos; a apropriação de diferentes discursos e a construção interacional do papel social de líder. Na conclusão, Bortoni-Ricardo verifica que os três paradigmas mencionados são conciliáveis e se 
complementam e que a hipótese de Le Page, em relação ao uso da linguagem como marca de identidade, contribui para esclarecer esse complexo processo, sobretudo se complementada por conceitos oriundos dos modelos interacionais de base fenomenológica e da sociologia das relações de poder.

Podemos verificar que essa obra não se restringe a um público limitado; ao contrário, constitui-se em uma valiosa contribuição para estudantes, professores, pesquisadores e demais interessados na Teoria Social do Discurso, no letramento como prática social, nas identidades de gênero, na educação, no discurso e nas suas relações com o gênero social, com a mídia, o poder, a alfabetização de adultos, a escola, a família e a comunidade. Essa amplitude deve-se tanto à questão temática quanto à forma de organização da obra e à linguagem usada pelos autores. Além disso, é importante destacar o quão profícua esta coletânea é como fonte de pesquisa, pois nos apresenta um vasto e atual referencial bibliográfico.

\section{REFERÊNCIAS BIBLIOGRÁfICAS}

Barton, D. \& Hamilton, M. Local literacies. London and New York: Routledge, 1998.

Barton, D., Hamilton, M. \& Ivanic, R. Situated literacies. London and New York: Routledge, 2000.

Bhabha, H. K. The location of culture. London and New York: Routledge, 1994.

Cameron, D. Verbal hygiene. Londres e Nova York: Routledge, 1995.

Chouliaraki, L. \& Fairclough, N. Discourse in late modernity: rethinking critical discourse analysis. Edinburgh: Edinburgh University Press, 1999.

Giddens, A. Modernity and self-identity: self and society in late modern age. Cambridge: Polity Press, 1991.

Hall, S. Identidades culturais na pós-modernidade. Trad. T. T. da Silva e G. L. Louro. Rio de Janeiro: DP\&A Editora, 1997.

Silva, T. T. (org.) Identidade e diferença. Petrópolis, RJ: Vozes, 2000. 